\title{
Structural Variation in the Nasal Bone Region of European Moose (Alces Alces L.)
}

\author{
By K. Nygrén, S. Paatsama and B. de Gritz \\ Institute of Game and Fischeries Research and \\ College of Veterinary Medicine, Helsinki, Finland.
}

\begin{abstract}
Nygrén, K., S. Paatsama and B. de Gritz: Structural variation in the nasal bone region of European moose (Alces Alces $L$.). Acta vet. scand. 1990, 31, 385-391. The ontogeny of typical (normal) nasal bone region of the European moose (Alces alces $L$.) and the 3 variants of the pattern, was studied. The variants, named as "extra bone type", "punctured type" and "open type" referring the morphology of the internasal suture, were originally observed in Finnish male and female moose skulls in 1971. All of the variants were later found in hunting trophy exhibitions presenting male moose trophies from Sweden, Norway, Baltic Republics of USSR and Poland. The frequencies of the variants showed regional differences. By using histological, radiological and OTC bone labelling methods, all of the nasal bone types were observed in this study in embryonal $(\mathrm{N}=36)$, newborn $(\mathrm{N}=21)$, juvenile $(\mathrm{N}=38)$ and adult $(\mathrm{N}=12)$ moose. Two twin embryos showed different nasal bone structure. The variation is considered to be of congenital origin.
\end{abstract}

sutures; ontogeny.

\section{Introduction}

The facial region of the moose head is long and kinetic. The short, broad nasal bones articulate on the midline by flat or slightly squamous sutures, laterally with the maxillary bones and caudally with the frontal bones. As in all cervid species, the nasolacrimal fissure is large, hence the nasal bones do not articulate with the lacrimal bones.

Observations of the nasal bone region of European moose skulls in hunting trophy exhibitions held in Finland since 1971, revealed 3 variations from the typical pattern. In the trophy exhibitions held in Poland 1980, and Sweden, Norway and Baltic Republics of USSR 1984, a similar variation was observed (Nygrén 1986). The normal nasal bone pattern consists of 2 intramembranously ossified transversally convex nasal bones with uninterrupted internasal suture. In the "extra-bone"-type there is a separated bone or a group of bones between the nasal bones separating the nasal bones caudally or completely. In the "punctured" type, the internasal suture is closed rostrally but opens in the middle of caudal parts, and in the "open" type the nasal bones do not touch (Fig. 1). Extra bones (called paranasals) were often observed along the nasolacrimal fissure in the older males regardless of which nasal bone pattern was present (Nygrén 1986). These bones were also observed in the American Cervalces and moose by Scott (1985).

This study deals with the ontogeny of the different nasal bone patterns of the moose from the embryonic to adult stages.

\section{Material and methods}

The gross anatomy of the nasal region of 27 embryos, from moose cows 3 to 6 months pregnant, was studied by radiography. Seven 


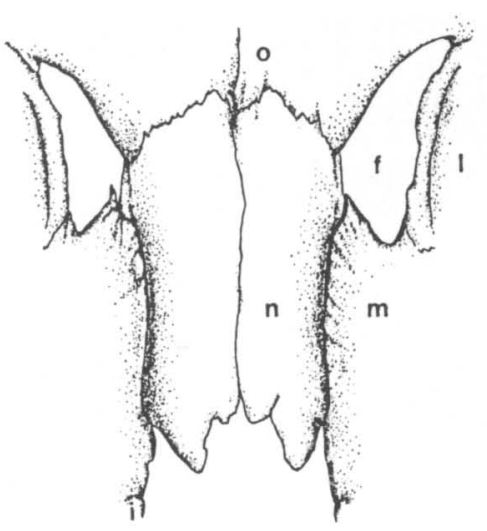

A

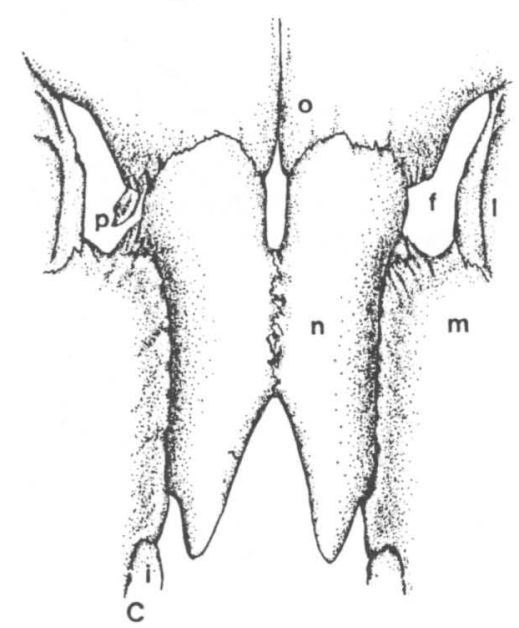

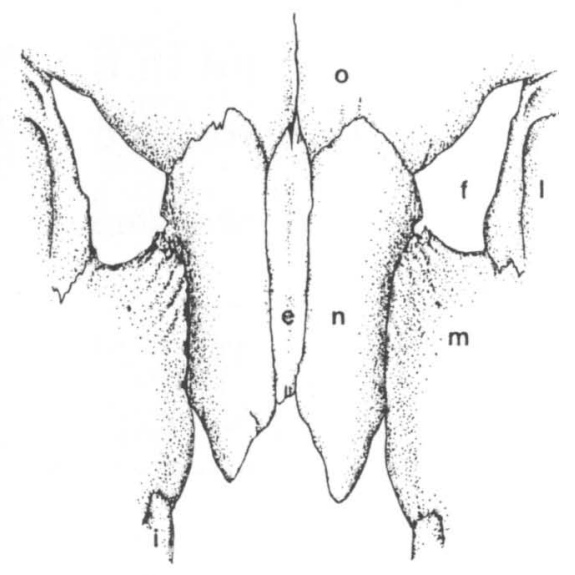

B

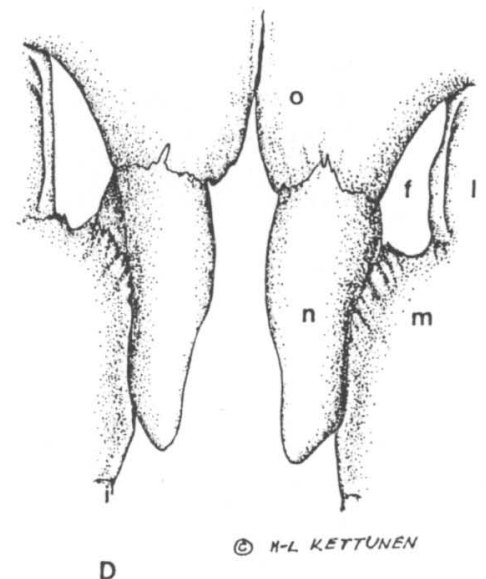

Figure 1. Nasal bone types of European moose. $A=$ normal, $B=$ extra bone, $C=$ punctured, $D=$ open type. $e=$ extra bone, $f=$ fissura nasolacrimale, $i=$ os incisivum, $1=$ os lacrimale, $m=$ os maxillare, $n=o s$ nasale, $o=o$ frontale, $p=o$ paranasale.

embryos were dyed in toto by use of the alizarin red $\mathbf{S}$ method for macroscopical examination (Lundvall 1904). Two embryos were studied histologically. Specimens fixed in $10 \%$ neutral formaldehyde (Lillie 1954) were decalcified by the New Decalc 0060 (Histo-Lab Ltd, Sweden). The paraffin-embedded 3-5 $\mu$ thick sections were stained by the hematoxylin-eosin, van Gieson's and Alcian blue methods (Romeis 1968).
Twenty one newborn calves, up to 1 month of age, were examined for nasal bone pattern by removing the skin of the fresh specimens. Five of these were also studied histologically with the same methods used on the embryos, and 5 by using oxytetracyclin (OTC) bone labelling method (Olsson \& Rietz 1966). For OTC fluorescence studies, $30 \mathrm{mg}$ oxytetracyclin (Terramycin ${ }^{\circledR}, \quad$ Pfizer) $/ \mathrm{kg}$ body mass was injected intraperitoneously 3 days before killing the animals. 

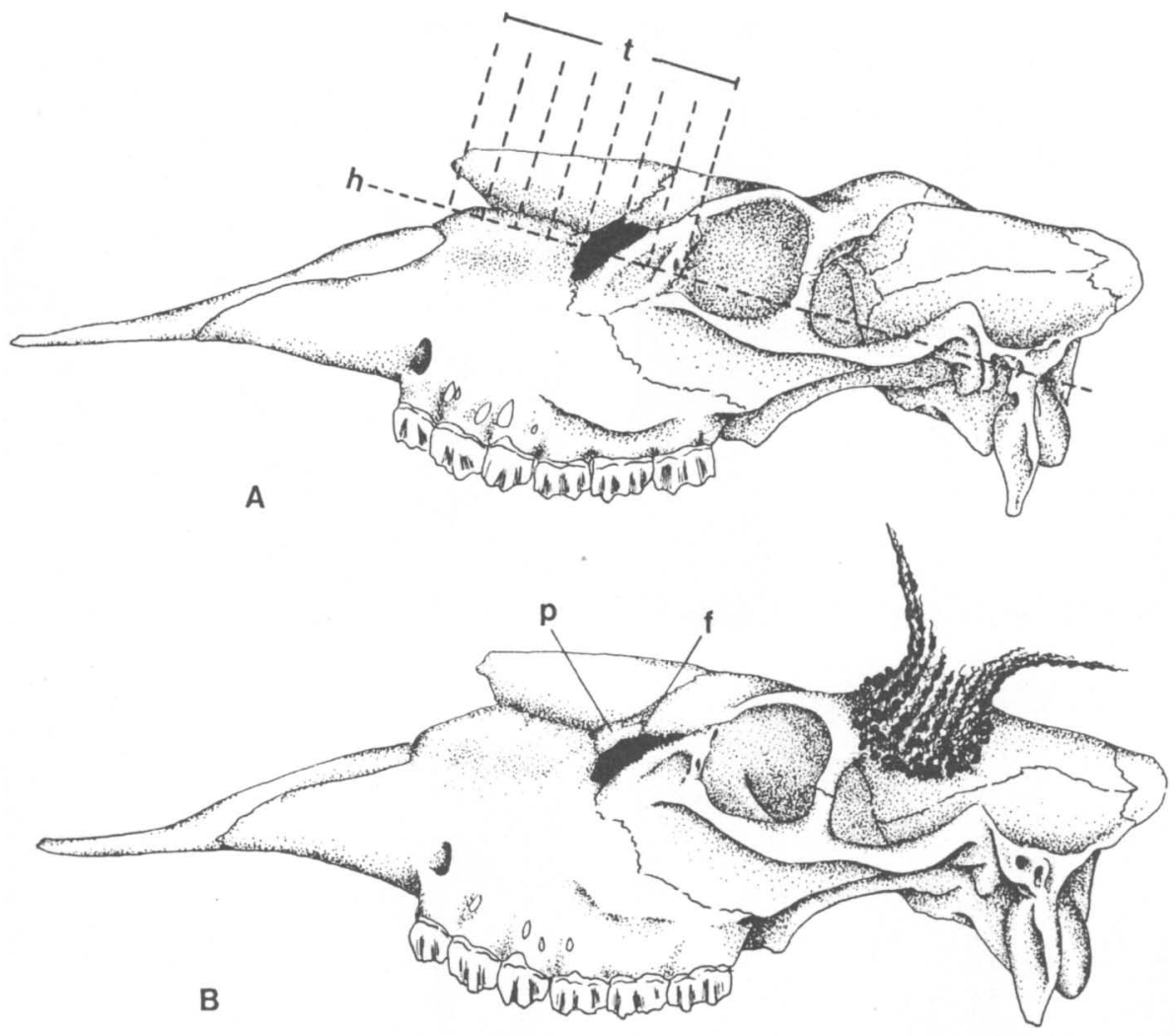

(C) M-L KETTUNEN

Figure 2. Lateral wiev of a skull of young (A) female and 8,5 years old (B) bull moose showing the nasolacrimal fissure $(f)$ and paranasal bone $(p)$. Horizontal $(h)$ and transversal $(t)$ sections of the skull are also illustrated.

The nasal region of 34 juvenile animals from 6 to 7 months of age, four 18 months old animals and 12 adults from 2.5 to 18 years of age was removed for nasal bone pattern determination. Ten were exposed ventrodorsally on Kodak X-Omat MA film with a Siemens triplex optimatic $x$-ray machine using 58-70 kV and 32-50 MaS exposure. After that, the specimens were cut into 2-3 cm thick transversal sections and exposed rostrocaudally (Fig. 2). Age was determined in growing animals by tooth eruption stages and in adults from dental cementum annuli (Sergeant \& Pimlott 1959).

\section{Results}

\section{Embryos}

Two embryos, although being twins, showed different nasal bone patterns; one had 2 differentiated nasal bones resembling a typical pattern, whereas the other had 3 small ossification centers between the nasal and frontal bones resembling the extra bone pattern. Histologically, the nasal bones showed intramembranous ossification in an early stage. The sutural histology showed Sharpey's fibers and collagenous fiber bundles. Fibroblasts and fibrocytes were more numerous in the vicinity of the margin of sutural bone. 

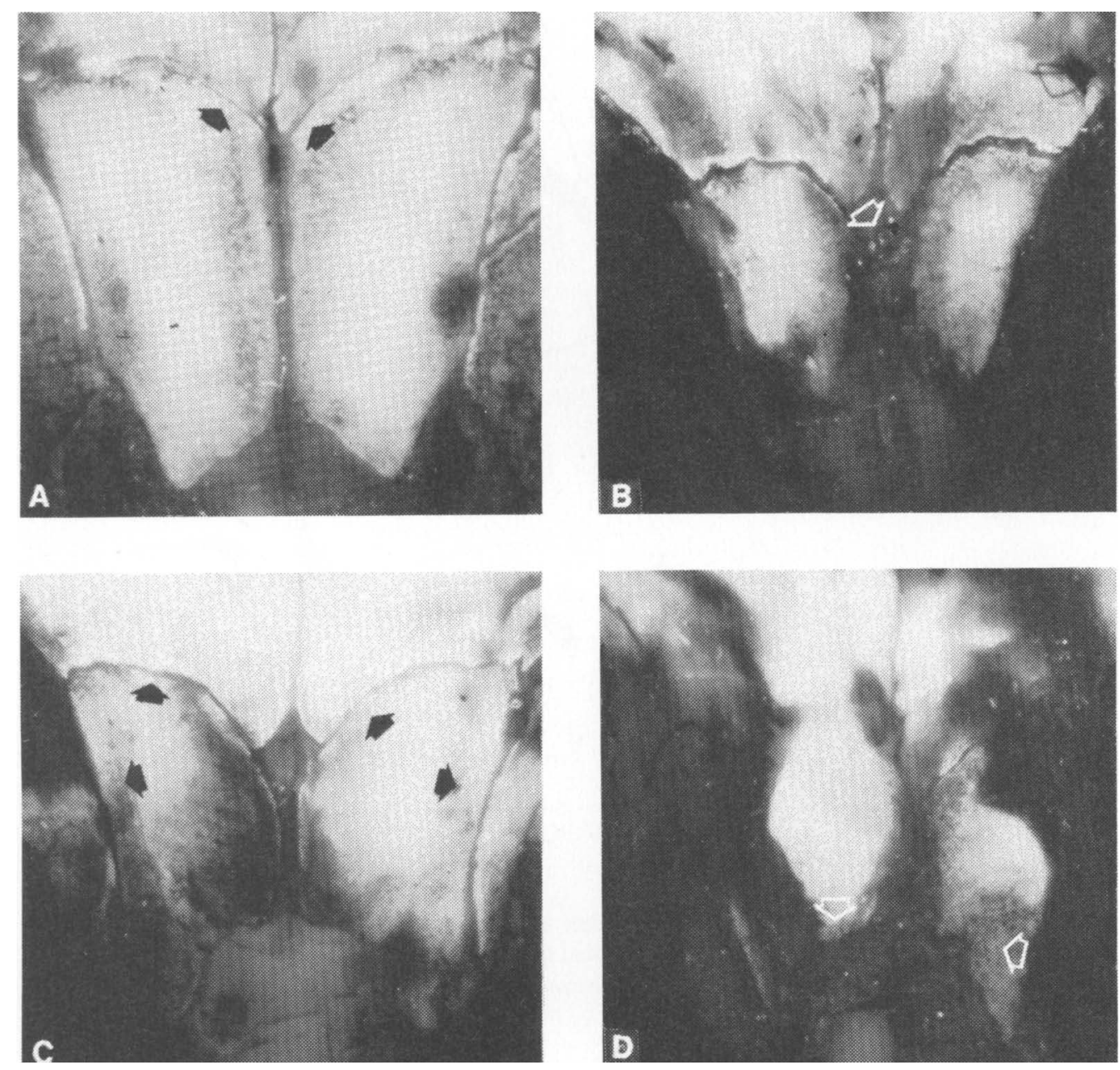

Figure 3. Fluorescence photograpgs of newborn calves ( 2 to 4 weeks). A: normal calf ( 4 weeks) showing weak OTC uptake of the nasal bones as a sign of already advanced stage of bone growth and strong uptake at the nasofrontal margin (arrows) as a sign of ossification activity; B: the extra bone type (3 weeks) shows a strong uptake at the margins and in clusters in the rostral parts. The extra bones show a strong uptake (arrow); C: the punctured type ( 3 weeks) showing a strong uptake at the margin areas (arrows) as a sign of growth activity in this area. The short rostral areas are lacking OTC uptake; D: open type showing notable deviation of the trunk and deformed nasal and frontal bones unilaterally and displaying weak uptake of the shorter normal nasal bone (arrow), and clustered uptake (arrows) in the deformed nasal bone. 


\section{Newborn calves}

Ten calves showed 2 ossified nasal bones with a broad, partly open suture, resembling the typical pattern. The internasal space of the extra bone pattern, as observed in 7 animals, consisted either of a partly ossified spindle shaped bone (4 specimens) or numerous small bones ( 3 specimens). In 2 of the specimens, the rostral part lacked the internasal suture. One calf displayed a punctured nasal bone pattern with the rostral part of the internasal suture partly open. Three calves showed an open nasal bone structure with broad internasal space $(8-20 \mathrm{~mm})$ and thin nasal bones. One of them also displayed unilateral deformation of nasal and frontal bones and a notable deviation of the rostral parts of the skull. Radiologically, all of the nasal bone types were found in newborn calves. The margins of nasal bones of the open pattern displayed more radiolucency. The

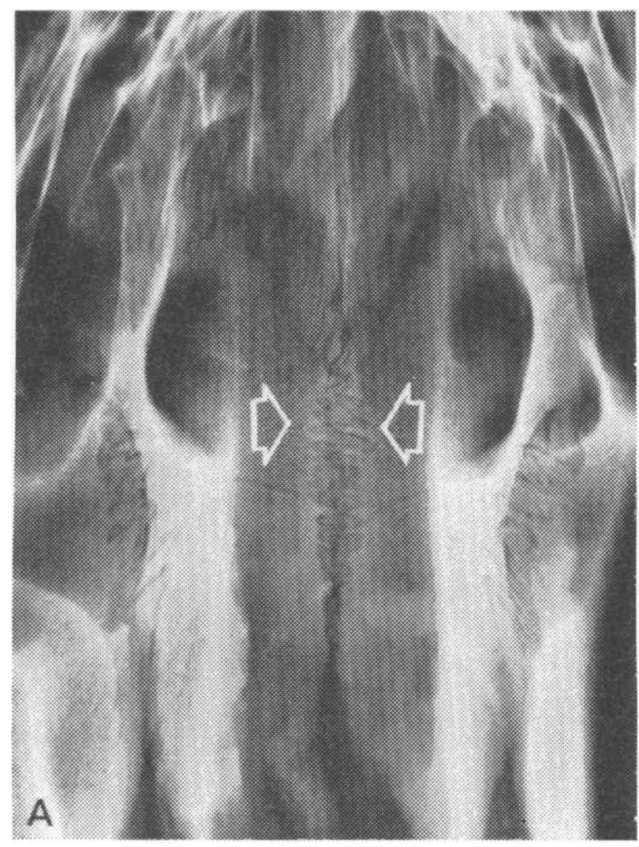

dorsal part of the nasal septum reached close to the internasal space and there were also ossified areas in the dorsal conchae close to the septum.

The nasal bones of a calf with normal pattern showed weak OTC uptage (Fig. 3). Those with the extra bone pattern showed strong uptake at nasofrontal and internasal sutural margins as well as in clusters in rostral areas. The extra bones showed strong uptake. In the punctured pattern, the OTC uptake was strong in the internasal suture. The calf with an open and deformed nasal bone structure showed a weak uptake in its short normal nasal bone exept for a narrow zone at the margins showing strong uptake. The deformed longer nasal bone showed uptake in clusters.

Histologically, the nasal bone ossification of calves with normal, extra bone and punctured patterns consisted of wowen bone. In the

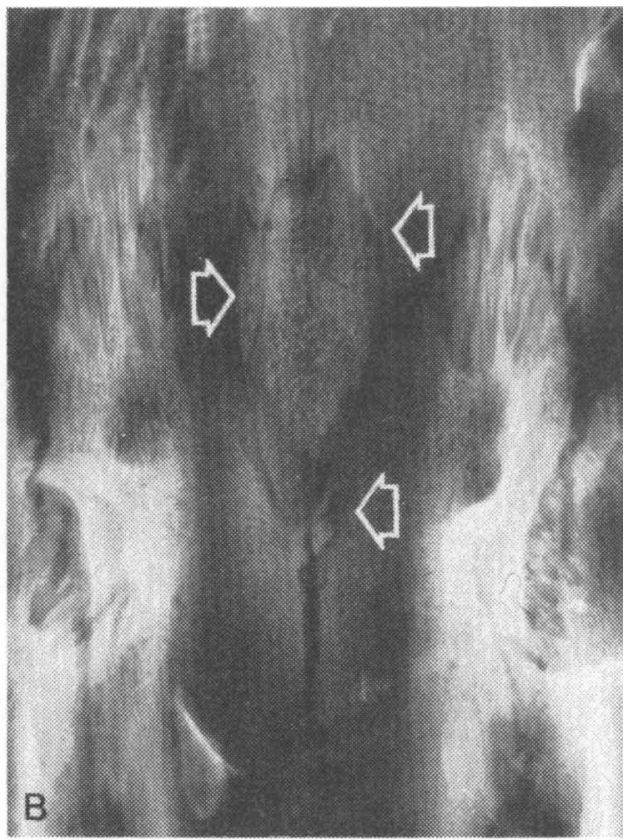

Figure 4. Ventrodorsal radiograph of a normal type (A) with a rough suture (arrows) and extra bone type (B) showing several extra bones (arrows) between the frontal and nasal bones. 

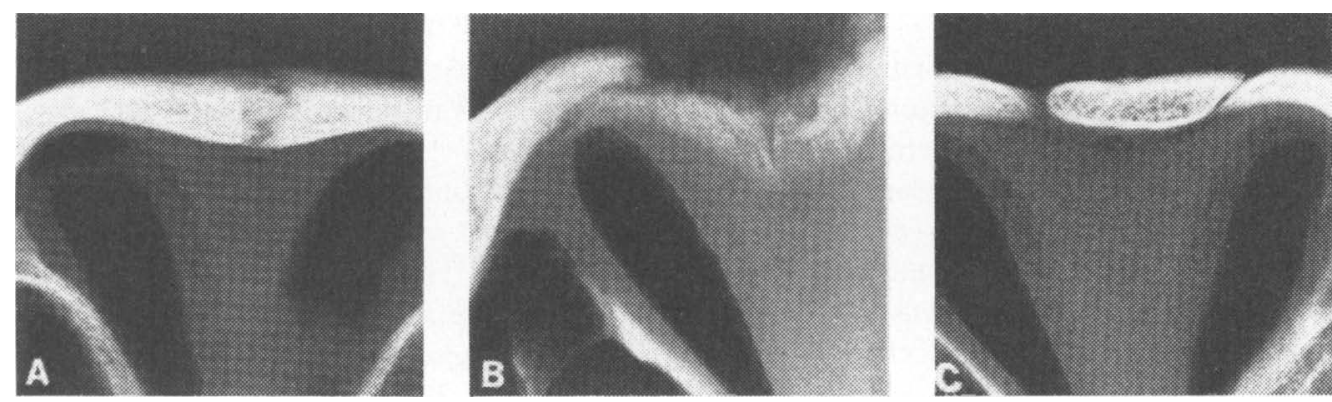

Figure 5. Rostrocaudal radiographs of transversal nasal sections. A: normal type; B: open type with dorsal concha and nasal septum showing ossification; C: extrabone type with single extra bone.

open pattern, the nasal bones showed intermembranous ossification in an early stage. All types displayed Sharpey's fibers and collagenous fiber bundles in a disorderly pattern. The extra bone pattern also showed primary centers of ossification and trabeculae of wowen bone incorporated with connective tissue of the internasal ligament. In the punctured pattern, this ligament was in contact with the cartilage of the nasal septum.

\section{Juvenile and adult animals}

Morphologically, there were no significant differences between the nasal structures of juvenile (1-2 years) and adult (2-24 years) moose. The type of internasal suture varied in both age groups. In those with the normal pattern, the suture was in most cases flat. In $19.7 \%$ of those with extra bone pattern there was no internasal suture. In others as well as in those with the punctured type, the internasal suture was squamous or interdigitated (Fig. 4). In the specimens with open pattern, the conchal areas and dorsal parts of the nasal septum showed ossification (Fig. 5). Histologically, in all of the juvenile animals the intramembranous ossification was in the lamellar stage. The sutural architecture was like newborn calves, exept for those with extra bones which histologically re- sembled lamellar bone and contained connective tissue and sinusoidal blood vessels.

\section{Discussion}

This study demonstrates 3 variations from the typical pattern of nasal bones in the European moose, from embryonic stages to adult. Three months old twin embryos displayed different nasal bone patterns, one of them typical and the other of the extra bone type. This indicates that the variations are of congenital origin.

The sutural architecture of the typical nasal bone as well as the 3 variations had 1 intramembranous ossification center for each nasal bone. This was verified with all the methods used. In addition, those with the extra bone pattern displayed separated ossification centers in the internasal space. One newborn calf with an open and deformed nasal bone structure showed OTC uptake in clusters. This indicates that a reparative bone formation was going on. A similar process was recognized in the bone regeneration of the femoral head (Paatsama et al. 1967). The internasal space of the open type was filled with fibrous connective tissue being structurally similar to the persistent fontanels of canine dwarf-breeds (Wiesner et Willer 1983). Nevertheless, other fontanel-like changes were not found in these moose 
skulls. The fontanels, considered as a potentially deleterious character, occur most commonly in connection with various diseases, congenital syndromes and developmental defects. The ossification of the dorsal conchae and dorsal parts of the nasal septum of the open type could be considered as a progressive repair process of the internasal space.

\section{References}

Lillie RD: Histopathologic Technic and Practical Histochemistry. The Blakiston Company, New York, Toronto 1954. $501 \mathrm{p}$.

Lundvall $H$ : Über Demonstration embryonaler Knorpelskelette. (The demonstration of embryonal cartilaginous skeleton). Anat. Anz. 1904, 25, 219-222.

Nygrén KFA: Der Elch. (The Moose). In: Niethammer J. \& F. Krapp (eds.): Handbuch der Säugetiere Europas. (Handbook of European mammals). Aula-Verlag, Wiesbaden 1986, 1 , 173-197.

Olsson SE, Rietz KA: Polymer osteosynthesis II. Acta chir. scand. Suppl. 367, 1966, 1-20.

Paatsama S, Rissanen P, Rokkanen P: Legg-Perthes Disease in the dog. J. Small Animal Pract. 1967, 8, 215-220.

Romeis B: Mikroskopische Technik. (Microscopic techniques). R. Oldenbourg Verlag Munich, Vienna $1968,757 \mathrm{p}$.
Sergeant D, Pimlott $D$ : Age determination in moose from sectioned incisor teeth. J. Wildl. Management 1959, 23, 315-321.

Scott WB: Cervalces americanus, a Fossil Moose, or Elk, from the Quaternary of New Jersey. Acad. Nat. Sci. Philadelphia 1985, 27, 181202.

Wiesner E, Willer S: Lexikon der Genetik der Hundekrankheiten. (Dictionary of genetics in canine diseases). S. Karger, Basel 1983, 120 121.

\section{Sammanfattning}

Näsbensregionens structurella variation hos den europeiska älgen (Alces Alces $L$ ).

Näsbensregionens normala ontogeni och dess tre olika varianter (extraben, ihålig och öppen) studerades hos den europeiska älgen (Alces alces $L$.) med alizarin red $\mathrm{S}$, radiologisk, histologiska och OTC-benfärgningsmetoder $(\mathrm{N}=107)$. Inga morfologiska skillnader observerades mellan näsbensregionerna av fostrarna samt växande och fullvuxna älg. Tre månader gamla tvillingsfostrarna visade sig vara av olika näsbensregionstyp. Alla näsben hade en ossifikationscenter. Dessutom observerades skilda ossifikationscentra i preparater av extrabenstyp. I öppen typ visade dorsala delar av conchae och septum nasi tecken av reparationsprocess. Variationen tycks vara av medfödd natur.

(Received February 15, 1989; accepted November 13, 1989).

Reprints may be requested from: K. F. A. Nygrén, Ahvenjärvi Game Research Station, SF-82900 Ilomantsi, Finland. 